\title{
Presença dos princípios da mentalidade enxuta e como introduzí-los nas práticas de gestão das empresas de transporte coletivo de Porto Alegre
}

\author{
Miguel Afonso Sellitto ${ }^{\mathrm{a}, *}$, Miriam Borchardt ${ }^{\mathrm{b}}$, Giancarlo Medeiros Pereira ${ }^{\mathrm{c}}$ \\ a,*sellitto@unisinos.br, UNISINOS, Brasil

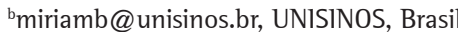 \\ 'gian@unisinos.br, UNISINOS, Brasil
}

\begin{abstract}
Resumo
Este artigo apresenta uma pesquisa que investigou a presença dos princípios da mentalidade enxuta na indústria do transporte coletivo de Porto Alegre. Os procedimentos foram: mensuração do grau de presença dos princípios da mentalidade enxuta na gestão das quinze empresas de transporte coletivo por ônibus de Porto Alegre; teste da confiabilidade das respostas e separação das empresas em aglomerados, segundo a intensidade da presença; e estudos de caso com os aglomerados extremos, a associação de classe e a operadora pública influente na indústria. Um achado dos casos é que a indústria tem capacidade de aprendizagem e aceitaria uma abordagem indutiva e prática, baseada em benchmarking, com operações de fabricação de classe mundial, para modificação de seus modelos de gestão. Também emergiu que a indústria teria dificuldades com abordagens dedutivas formalizadas, que incluam atividades acadêmicas.
\end{abstract}

Palavras-chave

Mentalidade enxuta em transportes. Benchmarking em transportes. Aprendizagem em transportes.

\section{Introdução}

0 número de passageiros do transporte coletivo nas capitais brasileiras diminuiu, aumentando os custos unitários e estimulando o uso do transporte particular (NTU, 2009; ANTP, 1999). Reconquistar a confiança, manter a qualidade, reduzir custos e garantir tarifas suportáveis são, atualmente, os maiores desafios que as empresas de transporte rodoviário urbano enfrentam (ANTP, 2001). Outras ações importantes, tais como planejamento urbano e ambiental e políticas para o transporte coletivo, dependem mais do poder público.

0 transporte de passageiros é atividade de alta complexidade, com comportamentos aleatórios, com não-linearidades e interações emergentes, que influenciam e são influenciados pelo ambiente e pelo sistema de gerenciamento (KHISTY; ARSLAN, 2005). O sistema de transporte de uma capital é composto por sub-sistemas que evoluem ao longo do tempo, tais como modais alternativos, tecnologia e estilo de vida. Em algumas capitais brasileiras, um resultado dessa evolução foi a queda na média mensal de passageiros transportados, de 1994 até meados dos anos 2000, como apresentado na Figura 1. A pesquisa ocorre nos meses de abril e outubro. A figura mostra os dados dos meses de abril de 1994 a 2007.

Uma alternativa gerencial para a indústria é a adoção de princípios e técnicas capazes de diminuir as perdas e aumentar os ganhos. Novas experiências têm sido testadas, tais como o modelo de gestão da ANTP (Associação Nacional de Transportadores de Passageiros) e a certificação 1SO 9001:2000, que objetivaram aumentar a qualidade e o valor percebido pelo cliente. Até quanto se pesquisou, práticas baseadas nos princípios da mentalidade enxuta ainda não foram propostas. Tais práticas poderiam reduzir o custo do serviço e, juntamente com o aumento da percepção de valor, reverter o ciclo de perdas mencionado.

Antes de uma eventual proposição, fez-se uma pesquisa cujo objetivo foi identificar como abordar a indústria para eventual modificação 


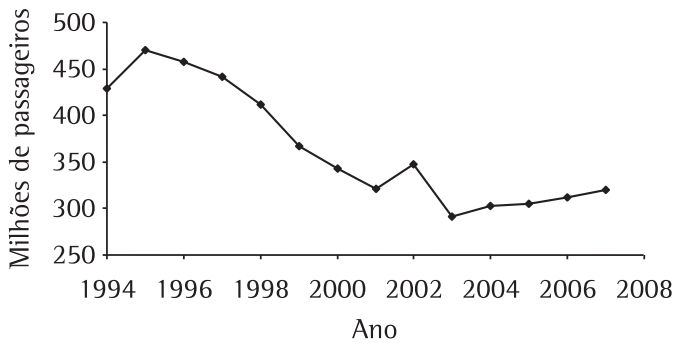

Figura 1. Média mensal de passageiros em capitais (São Paulo, Rio de Janeiro, Belo Horizonte, Recife, Porto Alegre, Salvador, Fortaleza, Curitiba e Goiânia) . Fonte: NTU (2009).

em suas práticas de gestão incluindo princípios da mentalidade enxuta. Os objetivos específicos foram: (i) mensurar quanto da mentalidade enxuta já estava presente nas empresas de uma capital; (ii) separar as empresas em três aglomerados, segundo a intensidade da presença: alta, média, baixa; e (iii) investigar, nos aglomerados alto e baixo, na operadora pública e na associação de classe, como introduzir a mentalidade enxuta. Os métodos foram, respectivamente: survey, análise de aglomerados e grupos focados. Por facilidade de acesso, a capital escolhida foi Porto Alegre. Este artigo é da mesma linha de pesquisa de Borchardt, Sellito e Pereira (2007).

0 restante do artigo está organizado em: (i) revisão sobre a indústria e a mentalidade enxuta; (ii) metodologia e resultados da pesquisa; e (iii) discussão dos resultados.

\section{Transporte coletivo em Porto Alegre}

Em Porto Alegre, o transporte coletivo por ônibus é regulamentado desde 1928, funcionando por permissão de linha e empresa. Atualmente, operam quinze empresas, uma pública e quatorze privadas (COSTA et al., 2001). Em 1992, as empresas foram organizadas em grupos, os consórcios. 0 consórcio Conorte tem 416 veículos e três empresas que atendem a bacia geográfica norte. 0 Unibus tem 370 veículos e seis empresas, que servem a bacia leste. 0 STS tem 447 veículos e cinco empresas, que atendem a bacia sul. As linhas transversais são mantidas pela Cia. Carris Porto-alegrense, empresa pública municipal com 323 veículos e que influencia a estratégia do setor (EPTC, 2007). Segundo o STS (2007), os consórcios apresentam vantagens: (i) ordenamento dos horários de linhas de bacias; (ii) criação de linhas rápidas, diretas e semidiretas; (iii) diminuição do tempo de viagens e flexibilidade em horários de maior demanda; e (iv) melhor qualidade na prestação do serviço.
0 equilíbrio econômico-financeiro do sistema é preservado por mecanismo de compensação financeira: empresas superavitárias, que operam linhas com custos inferiores à média, repassam parte da receita às empresas que operam em linhas deficitárias. A Câmara de Compensação Tarifária (CCT) opera os repasses. Os consórcios administram a compensação interna entre as empresas, com base em seus percentuais de custos (AZAMBUJA, 2002).

0 sistema de transporte coletivo em Porto Alegre é regulamentado pela Empresa Pública de Transporte e Circulação - EPTC. 0 órgão estabelece os critérios de produção, por tabelas horárias, que especificam horários, cargas, itinerários e requisitos de qualidade do serviço. Os requisitos são aferidos de tempos em tempos, junto aos usuários, através de pesquisas de informação, que detectam qualitativamente os mais relevantes para a satisfação deles e em que graus são satisfeitos. Cabe às empresas o gerenciamento para que se atinjam esses requisitos de desempenho e se cumpram os objetivos de produção. Dados dessas pesquisas, tomados como dimensões de desempenho, foram explorados por Sellitto e Borchardt (2004) em análise multivariada, que pode ser útil na formulação de estratégia de operação no setor.

A EPTC (2007) destaca que transportadores clandestinos ou irregulares praticamente inexistem na cidade e não há atividade de mototáxi. A empresa considera que ações estruturais tomadas até os anos 1980, tais como corredores exclusivos para ônibus e serviços regulamentados e fiscalizados de lotação e transporte escolar, desestimularam práticas clandestinas. No entanto, como em outras capitais, há queda no número de passageiros transportados (21,8\% entre 1998 e 2006) (Tabela 1). A empresa atribui a queda a fatores ligados à conjuntura social brasileira e não circunstanciais, como os clandestinos.

\section{Mentalidade enxuta}

A abordagem do lean management, desenvolvida por Taiichi Ohno, na Toyota Motor Corporation, forma a base do Toyota Production System TPS, aplicado preferencialmente em manufatura (MALEYEFF, 2006). Posteriormente, Womack e Jones (1998) propuseram o lean thinking (LT), estendendo o TPS a outros setores. O LT inclui ferramentas e formas sistêmicas de eliminação de perdas, pela concepção e projeto de produtos e processos e melhoria em atividades, interfaces e fluxos entre processos internos e externos. 0 lean thinking ou lean management tem sido descrito em 
Tabela 1. Média mensal de passageiros transportados em Porto Alegre. Fonte: EPTC (2007).

\begin{tabular}{lc}
\hline Ano & Média mensal \\
\hline 1998 & 33.593 .909 \\
1999 & 32.423 .097 \\
2000 & 31.771 .916 \\
2001 & 31.374 .419 \\
2002 & 30.358 .098 \\
2003 & 28.656 .169 \\
2004 & 27.549 .650 \\
2005 & 27.006 .678 \\
2006 & 26.282 .305 \\
\hline
\end{tabular}

manufatura e em serviços por autores, tais como: James-Moore e Gibbons (1997), Sánchez e Pérez (2001), Hines, Holweg e Rich (2004), Lewis (2000), Henderson e Larco (2002), Jackson e Jones (1996), Fullerton, McWatters e Fowson (2003). Neste artigo, o termo mentalidade enxuta foi usado tanto para lean thinking como lean management.

Operações de serviços e manufatura compartilham atributos de produção, agregando valor a entradas e criando um bem ou serviço final. A mentalidade enxuta enfoca processos e pode ser aplicada a ambos. Davis, Aquilano e Chase (2001) citam oportunidades de aplicação em serviços e em operações de serviços associadas a manufaturados. Bowen e Youngdahl (1998) apontam que organizações de serviços têm adotado princípios da produção enxuta (lean service) em processos de industrialização de serviços. Destacam que custos de serviços podem ser reduzidos pela eliminação de atividades que não agregam valor ao cliente.

Segundo pesquisas empíricas, cerca de 10\% apenas das empresas de manufatura têm sido bem-sucedidas na implementação de sistemas de produção enxuta. Um dos motivos que justificam o insucesso é que a mentalidade enxuta é mais do que técnicas e ferramentas padronizadas, requerendo mudanças na filosofia empresarial, negligenciadas nesses casos (BHASIN; BURCHER, 2006; EMILIANI, 2006; TREVILLE; ANTONAKIS, 2006).

A implementação da mentalidade enxuta requer elementos constitutivos baseados em gerenciamento interfuncional, trabalho em equipe, desenvolvimento organizacional, estratégia e cultura de melhoria contínua. Esta última se refere à capacidade de times analisarem problemas e desvios da estratégia e conceber, implementar e padronizar soluções efetivas (JACKSON; JONES, 1996; HENDERSON; LARCO, 2002; JAMES-MOORE; GIBBONS, 1997; ARNHEITER; MALEYEFF, 2005). Melhoria contínua dos processos por eliminação de perdas e foco permanente no cliente podem tornar a operação mais estável em ambiente de mudanças (COMM; MATHAISEL, 2005). Como os serviços ocorrem na presença do cliente, a gestão baseada na produção enxuta pode, por contato direto, tal como no transporte coletivo, gerar um ciclo virtuoso imediato de melhorias e aprendizado (PARASURAMAN, 2002). Aspectos relativos à melhoria contínua e a sistemas de gestão da qualidade têm sido abordados por autores como Prajogo e McDermott (2005); Kaynak (2003) e Sureshchandar, Chandrasekharan e Anantharaman (2001).

Para este artigo, a abordagem de Womack e Jones (1998), complementada por outros autores e adaptada para transporte coletivo rodoviário urbano:

1) determinar o valor do serviço: Hines e Taylor (2000) e Schonberger (1990) salientam que o valor a ser agregado pelo serviço deve ser determinado sob a perspectiva do cliente, ou seja, é necessário descobrir que dimensões dele interessam ao cliente e como seu atendimento pode estimulá-lo a adquirir o serviço;

2) identificar e acelerar a cadeia de valor: Porter (1999) define a cadeia de valor de uma operação de serviço como a reunião e o sequenciamento das atividades que são executadas para projetar, produzir, comercializar, entregar e sustentar o serviço: a aceleração da cadeia requer identificar e eliminar perdas empresariais;

3) fazer o valor fluir sem interrupções: Rother e Shook (1999) definem fluxo de valor como toda ação necessária para trazer os produtos e serviços requeridos pela operação através dos fluxos de serviço: devem ser ininterruptos e sincronizados, requerendo integração e velocidade nas interfaces entre processos internos e com processos externos;

4) adotar sistema de produção puxada: Um processo deve produzir apenas um bem ou serviço a partir da solicitação do processo posterior, que por sua vez atende ao próximo processo, até chegar aos clientes. Davis, Aquilano e Chase (2001) ressaltam a importância de sincronizar o tipo e a especificação da demanda com a capacidade e especificação de processos internos, fornecedores e parceiros externos, e destacam que a maior parte da sincronização em serviços tem a ver com o conhecimento das necessidades e mecanismos de captação da voz do cliente; e

5) buscar a perfeição: Os avanços nos demais passos não devem ser interrompidos por inércia ou falta de novos objetivos: eles podem ser alcançados por melhorias contínuas incrementais, o kaizen, e por melhorias radicais, o kaikaku. 


\section{A pesquisa}

0 objetivo geral de pesquisa foi identificar como abordar a indústria do transporte coletivo para eventual modificação em suas práticas de gestão incluindo princípios da mentalidade enxuta. Os objetivos secundários foram: mensurar a presença da mentalidade enxuta nas quinze empresas de transporte coletivo de Porto Alegre, separá-las em aglomerados forte, médio e fraco e estudar os aglomerados extremos e outros agentes para identificar como modificar práticas de gestão e incluir princípios da mentalidade enxuta. 0 primeiro objetivo responde à questão: quanto dos princípios da mentalidade enxuta está presente na indústria de transporte coletivo de Porto Alegre? Para questões do tipo quanto, Yin (2001) indica o survey. 0 terceiro objetivo responde à questão: como iniciar uma abordagem estruturada na indústria? Para questões do tipo como, Yin (2001) indica o estudo de caso. A pesquisa incluiu duas partes, uma mais quantitativa, para a primeira questão, outra qualitativa, para a segunda.

\subsection{Primeira parte}

Decidiu-se usar uma hierarquia para estruturar o termo "mentalidade enxuta em transporte coletivo". Uma hierarquia é composta por um termo teórico de topo, sustentado por construtos latentes, que se sustentam em conceitos representáveis por valores numéricos, os indicadores. Os valores dos indicadores podem ser combinados e formar o valor de topo que representa o termo teórico (SELLITTO; RIBEIRO, 2004). Entes de nível inferior devem ser mutuamente exclusivos e fornecer uma descrição exaustiva do nível superior, se bem que alguma perda de exclusividade, decorrente da subjetividade do observador, seja aceitável (FRENCH, 1986; HOGART, 1988; ESSLIN; MONTIBELLER; NORONHA, 2001).

Os construtos foram os princípios da mentalidade enxuta na linguagem da indústria: (i) capacidade de compreender o que agrega valor ao usuário; (ii) capacidade de eliminar perdas na cadeia de produção do serviço; (iii) capacidade de tornar a operação previsível; (iv) capacidade de sincronizar a operação ao interesse do usuário; e (v) capacidade de melhorar o resultado continuamente.

Cada construto foi estruturado em seis conceitos, em sessões de grupo focado, mediadas pelos pesquisadores e com três participantes da indústria: engenheiro, com mais de dez anos como gestor de empresa de transporte coletivo; engenheira especialista, com mais de quinze anos em órgãos públicos de planejamento de transportes; e administrador, com mais de quinze anos em empresas pública e privada de transporte coletivo. 0 método de trabalho dessa fase foi: (i) antes das sessões, treinamento teórico dos participantes em mentalidade enxuta; (ii) cinco sessões, uma para cada princípio, para estruturar os construtos; (iii) transformação da estrutura em questionário, remetido às empresas; (iv) teste da confiabilidade pelo alfa de Crombach; (v) formação de três aglomerados pelo método K-means; e (vi) sessão final do grupo focado para discussão dos resultados. A teoria e operação de grupos focados, o K-means e o alfa de Crombach são apresentados em Ribeiro e Newmann (2003), Hair et al. (1998) e Pereira (1999).

\subsection{Resultado da primeira parte}

Nas sessões de grupos focados, elaborou-se a estrutura da Figura 2. Cada construto foi dividido em seis conceitos, representados por indicadores a princípio mutuamente exclusivos. Usou-se por ora uma distribuição uniforme para a importância relativa dos elementos da estrutura. A distribuição de importâncias relativas foi estendida à continuidade.

A estrutura foi transformada em questionário (uma questão por conceito), observando-se aspectos relatados por Rea e Parker (2002): (i) inserir declaração com nomes e telefones dos pesquisadores, esclarecendo objetivos de pesquisa e critérios de seleção da amostra, alertando que não há respostas certas ou erradas, mas opiniões e percepções, e garantindo a confidencialidade; (ii) obedecer uma sequência lógica, dividindo o tema em partes constituintes e recriando o cenário mental de pesquisa no respondente; (iii) apresentar as opções segundo um padrão de respostas que possam ser tabuladas numericamente; e (v) testar a confiabilidade das respostas. Cada indicador foi avaliado por uma pergunta fechada, com cinco alternativas, em escala de likert [desempenho pleno $=5$; alto $=4$; médio $=3$, baixo $=2$; nulo $=1$ ]. (Segundo Gomes, Araya e Carignano (2004), a acuracidade humana para discernir características de objetos é limitada a sete qualidades mais ou menos duas.) As respostas são apresentadas na Tabela 2. 0 alfa foi calculado pelo software SPSS v.13.0. 0 questionário surge no apêndice 1.

Nas duas últimas linhas, têm-se a mensuração percentual da presença da mentalidade enxuta nas empresas e o posto dos respondentes. Na última coluna, têm-se os alfa de Crombach dos construtos, todos aceitáveis (Malhotra (2001) considera aceitáveis valores superiores a 60\%). Os conceitos que suscitaram mais dúvidas nos respondentes foram 


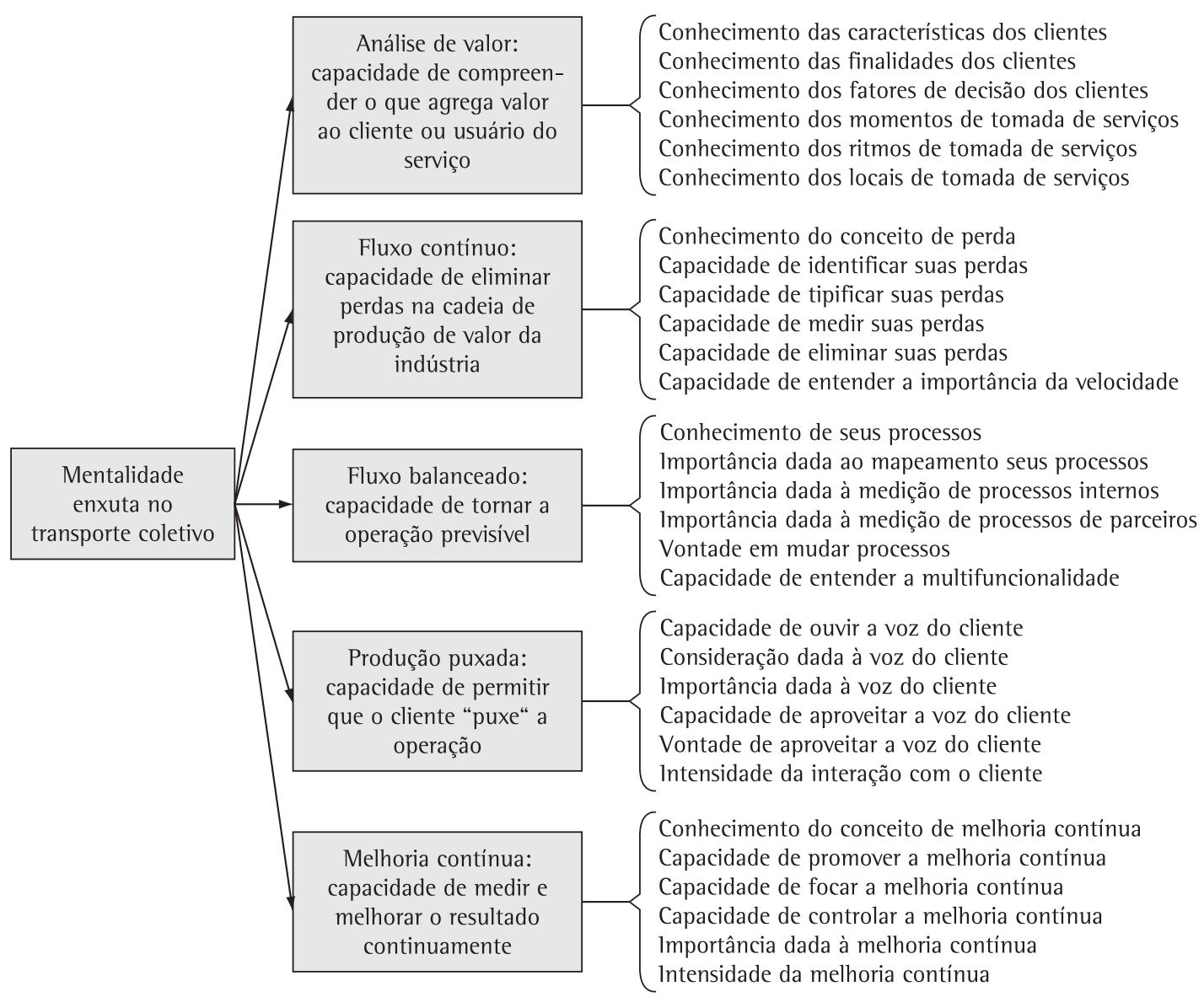

Figura 2. Estrutura da mentalidade enxuta em transporte coletivo.

importância dada à voz do cliente e capacidade de entender a multifuncionalidade. $\mathrm{Na}$ Tabela 3 , os casos foram aglomerados em presenças fraca, média e forte pela técnica $K$-means.

A visualização gráfica das empresas e aglomerados surge na Figura 3, na qual 1.1 é a primeira empresa do aglomerado 1 e assim por diante. Cada grupo de cinco colunas representa uma empresa e cada coluna tem altura proporcional à medição do construto. Pela distribuição das medições, é possível verificar as características dos aglomerados.

\subsection{Discussão da primeira parte}

0 papel da teoria foi importante na construção da estrutura hierárquica. Sem ela talvez não se chegasse à estrutura. 0 uso de indicadores categóricos permitiu a mensuração global do objeto, a identificação dos conceitos que mais suscitaram dúvidas e distribuição dos respondentes entre
37 e 88\% do máximo possível. 0 software ProConf 98 não rejeitou a hipótese de que os quinze valores pertençam a uma distribuição normal, com média 66,54 e desvio-padrão 17,47 pontos percentuais. A significância do ajuste é de 25\%. 0 intervalo de confiança a $95 \%$ vai de 38,18 a 94,9 pontos percentuais. A aglomeração por construto gerou três classes de empresas, com oito, quatro e três membros.

Os resultados foram apresentados aos três especialistas, em uma última sessão de grupo focado, que os examinaram e teceram comentários, cuja essência segue-se.

0 aglomerado forte contém oito empresas. A maior parte adota algum tipo de prática, tais como o modelo ANTP ou a certificação 1S0-9001:2000. Nestas, observam-se práticas de benchmarking, planejamento estratégico, medição de resultados por indicadores e BSC. As empresas têm recrutado gestores com formação em administração e engenharia, e estimulado métodos gerenciais. 
Tabela 2. Respostas e análise.

\begin{tabular}{|c|c|c|c|c|c|c|c|c|c|c|c|c|c|c|c|c|c|c|c|c|}
\hline & 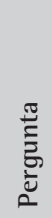 & 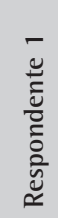 & 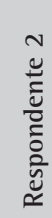 & 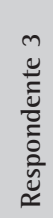 & 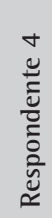 & 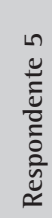 & 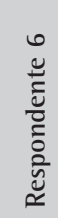 & 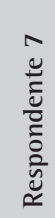 & 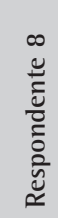 & 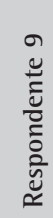 & 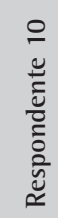 & 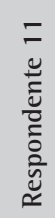 & 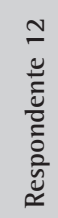 & 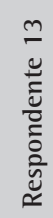 & 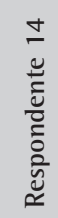 & 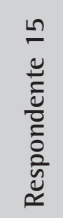 & हैँ & $\frac{\varepsilon}{0}$ & $\begin{array}{l}\frac{E}{0} \\
\frac{0}{0} \\
\frac{0}{0} \\
\frac{1}{2} \\
\frac{5}{0} \\
0\end{array}$ & 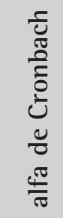 \\
\hline \multirow{6}{*}{ 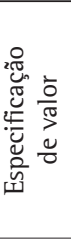 } & 1 & 5 & 4 & 4 & 4 & 2 & 4 & 5 & 3 & 3 & 4 & 2 & 4 & 3 & 2 & 2 & 51 & 21 & 343 & 0,57 \\
\hline & 2 & 4 & 4 & 4 & 5 & 3 & 4 & 4 & 4 & 3 & 5 & 3 & 5 & 3 & 2 & 3 & 56 & 14 & $3^{\circ}$ & \\
\hline & 3 & 4 & 4 & 3 & 4 & 4 & 4 & 4 & 4 & 3 & 5 & 4 & 4 & 3 & 2 & 3 & 55 & 17 & & \\
\hline & 4 & 5 & 5 & 4 & 5 & 4 & 4 & 4 & 5 & 1 & 5 & 5 & 4 & 4 & 4 & 3 & 62 & 8 & & \\
\hline & 5 & 5 & 4 & 4 & 4 & 5 & 5 & 4 & 5 & 1 & 5 & 5 & 4 & 4 & 3 & 2 & 60 & 9 & & \\
\hline & 6 & 4 & 4 & 4 & 4 & 5 & 5 & 4 & 4 & 3 & 5 & 3 & 4 & 4 & 3 & 3 & 59 & 10 & & \\
\hline \multirow{6}{*}{ 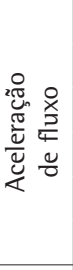 } & 7 & 4 & 3 & 4 & 3 & 3 & 4 & 3 & 1 & 4 & 4 & 2 & 4 & 3 & 1 & 2 & 45 & 25 & 268 & 0,32 \\
\hline & 8 & 4 & 4 & 5 & 2 & 2 & 4 & 4 & 1 & 3 & 4 & 3 & 4 & 3 & 1 & 2 & 46 & 24 & $5^{\circ}$ & \\
\hline & 9 & 4 & 4 & 4 & 3 & 3 & 4 & 3 & 1 & 3 & 4 & 3 & 3 & 2 & 1 & 2 & 44 & 28 & & \\
\hline & 10 & 3 & 4 & 4 & 3 & 3 & 4 & 4 & 1 & 3 & 4 & 3 & 3 & 2 & 1 & 3 & 45 & 25 & & \\
\hline & 11 & 5 & 5 & 4 & 5 & 4 & 5 & 4 & 1 & 4 & 4 & 1 & 4 & 1 & 1 & 1 & 49 & 22 & & \\
\hline & 12 & 3 & 3 & 3 & 3 & 3 & 2 & 3 & 3 & 3 & 3 & 3 & 3 & 1 & 1 & 2 & 39 & 29 & & \\
\hline \multirow{6}{*}{ 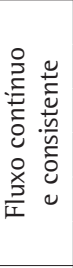 } & 13 & 5 & 5 & 5 & 5 & 5 & 5 & 5 & 4 & 5 & 5 & 3 & 4 & 4 & 5 & 4 & 69 & 1 & 345 & 0,87 \\
\hline & 14 & 5 & 4 & 5 & 4 & 5 & 5 & 4 & 1 & 4 & 5 & 1 & 1 & 1 & 5 & 5 & 55 & 17 & $2^{\circ}$ & \\
\hline & 15 & 5 & 5 & 5 & 5 & 5 & 5 & 5 & 1 & 4 & 5 & 1 & 4 & 4 & 5 & 5 & 64 & 6 & & \\
\hline & 16 & 5 & 5 & 5 & 5 & 4 & 5 & 1 & 4 & 1 & 5 & 1 & 4 & 4 & 4 & 5 & 58 & 11 & & \\
\hline & 17 & 5 & 5 & 4 & 4 & 4 & 5 & 4 & 4 & 1 & 5 & 4 & 4 & 4 & 5 & 5 & 63 & 7 & & \\
\hline & 18 & 2 & 3 & 2 & 2 & 2 & 1 & 3 & 3 & 3 & 3 & 3 & 3 & 2 & 2 & 2 & 36 & 30 & & \\
\hline \multirow{6}{*}{ 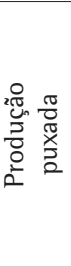 } & 19 & 5 & 5 & 4 & 4 & 3 & 5 & 5 & 1 & 4 & 5 & 1 & 5 & 5 & 1 & 5 & 58 & 11 & 379 & 0,76 \\
\hline & 20 & 5 & 5 & 4 & 4 & 4 & 5 & 5 & 5 & 4 & 5 & 2 & 5 & 5 & 4 & 5 & 67 & 3 & $1^{\circ}$ & \\
\hline & 21 & 5 & 4 & 4 & 4 & 5 & 5 & 5 & 4 & 4 & 5 & 5 & 4 & 4 & 4 & 5 & 67 & 3 & & \\
\hline & 22 & 5 & 4 & 4 & 4 & 5 & 5 & 4 & 4 & 4 & 5 & 4 & 4 & 5 & 4 & 4 & 65 & 5 & & \\
\hline & 23 & 5 & 5 & 5 & 5 & 4 & 5 & 4 & 5 & 4 & 5 & 4 & 4 & 5 & 4 & 5 & 69 & 1 & & \\
\hline & 24 & 4 & 4 & 4 & 4 & 2 & 5 & 4 & 3 & 3 & 4 & 4 & 3 & 4 & 3 & 2 & 53 & 19 & & \\
\hline \multirow{6}{*}{ 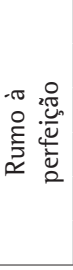 } & 25 & 5 & 4 & 5 & 4 & 4 & 4 & 5 & 1 & 4 & 4 & 3 & 4 & 3 & 2 & 4 & 56 & 14 & 313 & 0,61 \\
\hline & 26 & 5 & 5 & 5 & 5 & 5 & 5 & 4 & 1 & 4 & 5 & 1 & 4 & 1 & 1 & 5 & 56 & 14 & $4^{\circ}$ & \\
\hline & 27 & 5 & 5 & 5 & 5 & 1 & 5 & 4 & 1 & 4 & 5 & 1 & 4 & 1 & 1 & 5 & 52 & 20 & & \\
\hline & 28 & 5 & 5 & 4 & 5 & 4 & 5 & 4 & 1 & 4 & 5 & 1 & 4 & 4 & 1 & 5 & 57 & 13 & & \\
\hline & 29 & 5 & 5 & 4 & 1 & 1 & 5 & 4 & 1 & 4 & 4 & 1 & 4 & 4 & 1 & 3 & 47 & 23 & & \\
\hline & 30 & 4 & 4 & 3 & 3 & 3 & 4 & 3 & 1 & 3 & 4 & 2 & 3 & 3 & 1 & 4 & 45 & 25 & & \\
\hline \multirow{2}{*}{\multicolumn{2}{|c|}{$\begin{array}{l}\text { \% do máx. } \\
\text { ordem }\end{array}$}} & 88 & 83 & 78 & 73 & 64 & 86 & 74 & 40 & 57 & 88 & 41 & 70 & 55 & 38 & 63 & & & & \\
\hline & & 2 & 4 & 5 & 7 & 9 & 3 & 6 & 14 & 11 & 1 & 13 & 8 & 12 & 15 & 10 & & & & \\
\hline
\end{tabular}

Tabela 3. Aglomeração dos respondentes.

\begin{tabular}{cl}
\hline Presença & \multicolumn{1}{c}{ Respondentes } \\
\hline Forte & $1 ; 2 ; 3 ; 4 ; 6 ; 7 ; 10 ; 12$ \\
Média & $5 ; 9 ; 15$ \\
Fraca & $8 ; 11 ; 13 ; 14$ \\
\hline
\end{tabular}

Boa parte delas ou já concorreu ao prêmio ANTP de excelência em gestão ou estimulou gestores a conhecê-lo e discuti-lo. Essas empresas definitivamente incorporaram alguns dos princípios capitulados na mentalidade enxuta.
0 aglomerado fraco contém quatro empresas. Preocupando-se menos com gestão, elas vêm mantendo práticas ancoradas em cultura organizacional própria e em relações de poder centralizadas. Desconheciam abordagens estruturadas para esforços gerenciais, portanto não há histórico de programas e de resultados. Também não foram percebidos esforços para introdução de métodos gerenciais atualizados ou incentivo à formação superior de gestores. Considere-se que, na indústria, os custos de operação são compensados 


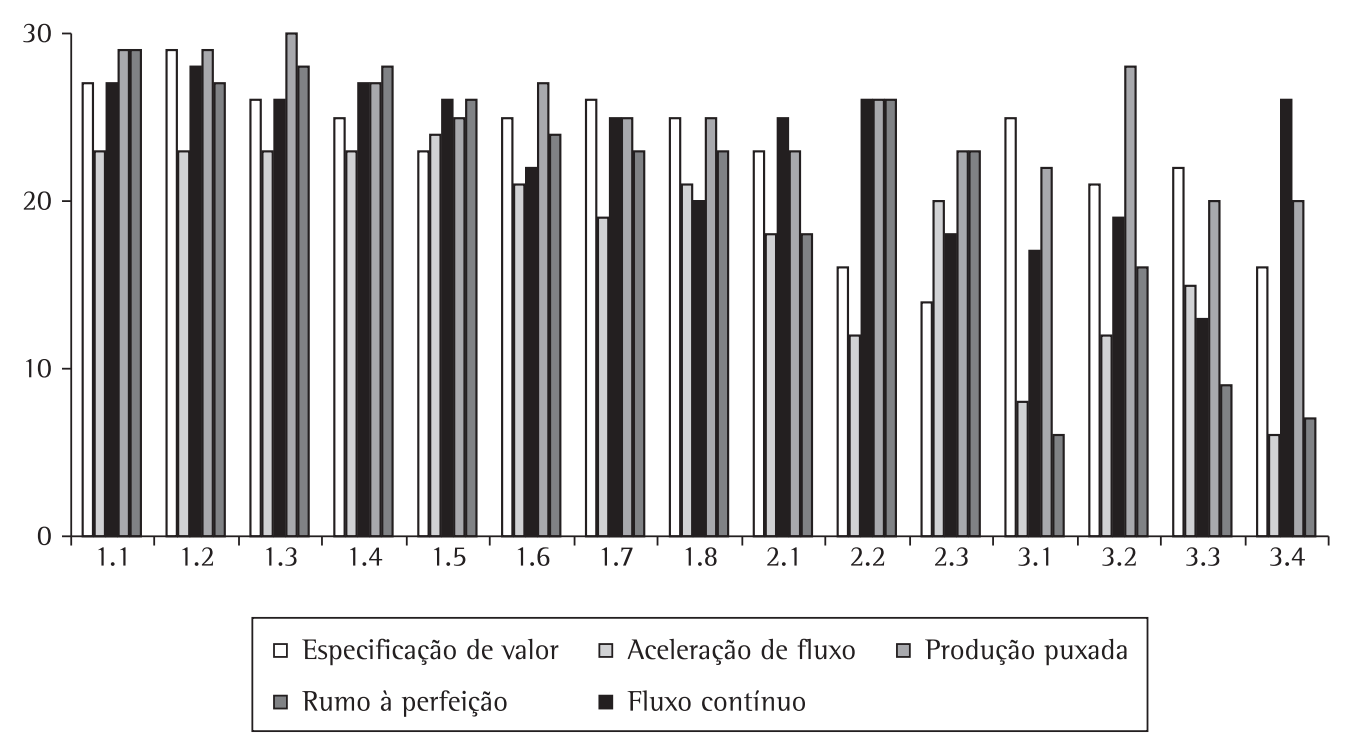

Figura 3. Visualização dos aglomerados.

na distribuição da arrecadação. Portanto, nessas empresas, a preocupação com resultado ainda está mais ligada à apuração de custos e à solução de problemas operacionais, não à busca da satisfação total do usuário, integração de práticas via consórcio ou ampliação do negócio.

Nas empresas do aglomerado médio, os princípios da mentalidade enxuta foram observados em grau intermediário. Tal situação parece resultar de ações intuitivas, em resposta ao ambiente de competição. Não foi percebido interesse no modelo ANTP, apenas esforços estruturados de redução de custo, que podem ter levado as empresas a incorporar, ao menos intuitivamente, algumas práticas da mentalidade enxuta.

Os praticantes também comentaram os conceitos que mais dúvidas suscitaram: importância dada à voz do cliente e capacidade de entender a multifuncionalidade.

Quanto ao primeiro, os praticantes observaram que pode haver dúvidas, sim, na indústria quanto a quem é o cliente. 0 termo usuário também é usado. Os praticantes consideraram que usuário é o passageiro, aquele que se desloca de ônibus. 0 cliente pode ser o órgão gestor público, que traça diretrizes de ação e retribui com avaliações de desempenho; o consórcio, que cobra práticas cooperativas e retribui com parcelas da arrecadação; ou o comprador do vale-transporte, que os distribui entre usuários. A diversidade de sentido pode explicar a menor confiabilidade observada na medição do indicador.

Quanto ao segundo, os praticantes observaram que o conceito é pouco mencionado na indústria. Não conhecem relatos de multifuncionalidade. Ao contrário, relataram restrições legais e operacionais quanto a motoristas, cobradores, arrecadadores, mecânicos e eletricistas veiculares. Funcionários que negociam diretrizes, avaliação de desempenho, vistorias, acidentes e novas rotas com o órgão gestor têm restrições estratégicas. As empresas mantêm poucas pessoas em contato com o órgão, para prevenir más interpretações. 0 mesmo vale para atendimento e comunicação com clientes e usuários. Funções ligadas a comportamento sofrem restrição ética: as empresas preferem que poucos funcionários, escolhidos e treinados, tenham acesso a históricos comportamentais e psicológicos de tripulantes. Desse modo, segundo os praticantes, para continuar na estrutura, o indicador deve ter a sua descrição adaptada à linguagem da indústria. A presença do indicador na estrutura foi sugerida pelos praticantes, que consideraram desejável uma ruptura de barreiras funcionais e mais integração entre funções. A falta delas, segundo eles, pode acarretar lentidão no atendimento a diretrizes legais e a solicitações de usuários.

\subsection{Segunda parte}

Nesta parte, o objetivo foi descobrir como poderiam ser conduzidos esforços para eventuais modificações em práticas de gestão, introduzindo os princípios da mentalidade enxuta. Os objetivos secundários foram identificar: (i) a natureza e as crenças que fundamentam as atuais práticas de gestão da indústria; (ii) a capacidade da indústria em compreender conceitos e modificar crenças; e (iii) o tipo de esforço para que a indústria mude conceitos e crenças. 0 método de pesquisa foi 0 estudo de caso. 
Como técnica de pesquisa, foram formados quatro grupos focados com membros: (1) de uma empresa do aglomerado fraco; (2) de uma do aglomerado forte; (3) da associação de classe; e (4) da operadora pública. Nos grupos 1 e 2, houve duas etapas: uma sem preparação, outra após leitura sobre a mentalidade enxuta. Prestadores de serviços mecânicos não participaram. Em entrevistas preliminares, verificou-se que eles não se percebem como elo da cadeia, talvez por atender a diversos setores, com várias estratégias.

Os grupos foram de quatro executivos com formação técnica e experiência operacional e administrativa. As reuniões ocorreram nas sedes das empresas. Foram previstos quarenta e cinco minutos por reunião, mas todas ocuparam mais de uma hora. Não houve insatisfação, indicando que o tempo foi subestimado. As perguntas não foram previamente informadas. 0 pesquisadores revezaram-se como moderadores. Foram acordados os objetivos, a forma de trabalho, o modo de apresentação dos resultados e a confidencialidade. Para os grupos 1 e 2, foi marcada uma segunda reunião.

Como fio condutor sugerido por Ribeiro e Newmann (2003), elaboraram-se questões: (i) inicial; (ii) de transição; (iii) centrais; (iv) de resumo; e (v) final.

A questão inicial objetivou tranquilizar os participantes e descontrair o ambiente, explorando a relação entre o conceito de perdas e prosperidade. A questão foi: Na opinião do grupo, por que países arrasados por guerras como Japão e Coreia são hoje tão prósperos?

A questão de transição encaminhou a discussão para o foco do problema: Na opinião do grupo, por que hoje nas empresas se trabalha cada vez mais e parece que o resultado é cada vez mais difícil de ser alcançado?

As questões centrais enfocaram definitivamente o problema: (i) Na opinião do grupo, sua empresa está obtendo o melhor resultado que o ambiente de negócios permite? Como esse ambiente tem se comportado?; (ii) Que critérios a empresa adota para medir resultados? Esses critérios variam?; (iii) A empresa sabe onde deve concentrar o esforço para aumentar o resultado?; e (iv) A empresa já desenvolveu uma abordagem estruturada para focar seu esforço? Se positivo, que resultados foram observados?

A próxima questão resumiu e finalizou a análise: Em resumo, na opinião do grupo, é possível trabalhar menos e obter mais resultado?

A questão final encaminhou a continuidade da pesquisa: A empresa examinaria a hipótese de desenvolver uma abordagem estruturada para focar esforços e melhorar resultados? Nos grupos 1 e 2, foi entregue material teórico sobre perdas empresariais e conceitos da mentalidade enxuta para a próxima sessão. Nos demais, encerrou-se aqui.

$\mathrm{Na}$ segunda sessão das operadoras se repetem as questões inicial, de transição e resumo para verificar o efeito da leitura. As questões centrais foram modificadas: (i) A empresa pode obter o melhor resultado que o ambiente de negócios permite?; (ii) A empresa pode estar medindo mal os resultados?; (iii) A empresa pode estar concentrando mal o esforço para aumentar o resultado?; e (iv) Se já houve uma abordagem estruturada para focar esforço e o resultado não foi positivo, qual a causa do insucesso? A questão final foi modificada: A empresa participaria de um seminário sobre perdas empresariais e que introduza a mentalidade enxuta? Que tópicos esse instrumento deveria contemplar?

\subsection{Resultado da segunda parte}

A primeira questão tinha como objetivo, além da quebra de eventual resistência, investigar se as empresas entendiam a competitividade como decorrência de processos de redução de perdas e eliminação de desperdícios. Nenhum dos quatro grupos demonstrou entender essa relação. 0 grupo 1 apontou fatores intangíveis, tais como cultura milenar, disciplina, hierarquia, educação, contrastando com a realidade brasileira, principalmente educação e organização política. Os demais grupos apontaram fatores menos abstratos, tais como gerenciamento eficaz, foco no negócio, gerenciamento de processos e capacidade de aprender com os erros. Esperava-se que emergisse a ideia de redução de custos e aumento de competitividade associada a combate ao desperdício.

Na segunda reunião, após a leitura do texto, o grupo 1 evoluiu, abandonando a concepção mítica do fenômeno e adotando uma mais concreta. 0 grupo falou em ousadia, determinação e métodos de gestão. Após a leitura, o grupo pareceu ter alcançado um patamar similar ao inicial dos outros grupos. 0 grupo 2 falou em estratégia e planejamento estratégico, avançando em direção à resposta esperada, se bem que não a encontrasse na plenitude, de modo autônomo. Ao ser apresentado à ideia de associar o progresso material à redução de desperdícios, o grupo a julgou possível e provável. Concluiu-se que a leitura surtiu efeito, indicando capacidade e vontade de aprendizado.

A segunda questão investigou até que ponto as empresas compreendiam o conceito de 
especificação de valor. Perguntou-se se a empresa concordava que seus esforços crescem em ritmo maior do que o dos resultados. Se positivo, qual a razão desse desequilíbrio. Essa é a realidade do setor. Os resultados têm caído, devido à redução de passageiros, e as empresas têm exigido esforços crescentes dos quadros, inclusive introduzindo as certificações 1SO 9000:2000. 0 grupo 1 não reconheceu o desequilíbrio e justificou a queda de resultados por empobrecimento da população, competição exagerada e individualismo. Para o grupo, o trabalhador antigamente era mais esforçado, mais comprometido com a empresa, havendo mais oferta de trabalhadores para seleção e treinamento. Alguns trechos literais: "falta respeito... pessoal escondido nas crises... antes as pessoas davam mais o sangue, hoje são individualistas..." Apontam o fator humano para reverter a queda no resultado. Já os demais grupos, além de concordarem com a afirmação, indicam ineficiências de processo como causa do desequilíbrio. Não individualizaram a falta de especificação de valor como causa para a ineficiência em processos, mas apontam que o mapeamento de processos pode reduzir desperdício. 0 grupo 2 ressaltou a globalização, as transformações políticas e a abertura de mercados como causas do acréscimo de competitividade. 0 grupo 3 apontou a atual velocidade nos negócios principalmente à introdução de novas tecnologias. 0 grupo 4 atribuiu o desequilíbrio à ineficiência intrínseca dos processos planejados e não revisados. Após a leitura, a resposta do grupo 1 evoluiu. 0 grupo inseriu as expressões "esforços fora de foco" e "investimentos onde o cliente não vê". Pela primeira vez, surgiu clara referência ao objetivo da pergunta: a especificação do valor na perspectiva do cliente. A resposta do grupo 2 praticamente não mudou, acrescentando a expressão "fora de foco" aos atuais esforços. Os grupos 1 e 2, quando apresentados à ideia de especificação de valor, julgaram-na possível de explicar o desequilíbrio entre esforços e resultados.

0 objetivo da terceira questão era verificar os conceitos de fluxo e balanceamento de processos e melhoria contínua. 0 grupo 1 concordou que 0 resultado pode ser melhor e apontou como causas: concorrência predatória, pouca união de esforços entre empresas, pouca profissionalização no setor e mercado cativo e cadente. Sobre medição de resultados, alegaram empregar pesquisas qualitativas de satisfação dos clientes. Quanto ao ponto para concentrar esforços, apontaram o fator humano. Não desenvolveram abordagens estruturadas para concentração de esforços, portanto não existe histórico de resultados. 0 grupo 2 visualiza com clareza que o resultado poderia ser melhor se houvesse mais adequação dos serviços aos objetivos do cliente. Mais uma vez apareceu a ideia de especificação de valor, mesmo não sendo esse o objetivo da questão. Quanto às medições, a empresa usa indicadores vitais e secundários, acompanha diariamente os vitais e preocupa-se com custos. 0 grupo sabe focar esforços, emprega pesquisas com clientes e funcionários, endomarketing, busca por desperdícios e benchmarking, embora não sistematizado. Usam como abordagem estruturada o planejamento estratégico e a melhoria contínua.

Os grupos 3 e 4 apresentaram respostas similares. Aceitam que o resultado pode ser melhor e que o ambiente de negócios muda com velocidade cada vez maior. Os resultados têm sido medidos preferencialmente por indicadores econômicos, indicadores de processo, responsabilidade social e recursos humanos. São formadas séries históricas que servem como referência para objetivos futuros. As empresas não sabem onde focar os esforços, se bem que tenham diagnósticos periódicos. Há abordagens estruturadas permanentes, tais como o planejamento estratégico, com resultados significativos e continuados, e abordagens pontuais, com resultados pouco conhecidos.

Após a leitura do texto, as respostas do grupo 1 variaram significativamente. 0 grupo entendeu que pode estar medindo mal o resultado, ou nem está medindo em alguns casos, reconheceu divergências nos focos de trabalho, principalmente porque a empresa não unifica visões sobre problemas. Reconheceu que nunca houve uma abordagem estruturada para melhoria de resultados, limitando-se a apagar incêndios. As abordagens tentadas no passado falharam devido à descrença e diferenças de ponto de vista entre membros da administração. As respostas do grupo 2 praticamente não variaram, acrescentando apenas a necessidade de estruturação nas abordagens citadas. Novamente, a leitura foi útil, pois os elementos objetivados pelo pesquisador apareceram na segunda rodada do grupo 1 .

0 objetivo da quarta pergunta era resumir os objetivos já alcançados e encaminhar um fechamento. 0 grupo 1 insistiu que ulteriores melhorias de resultado só serão possíveis pelo desenvolvimento de recursos humanos, incluindo atividades e engajamento voluntários. 0 grupo 2 apontou a análise de processo e modificações baseadas na busca de não conformidades. As respostas dos grupo 3 e 4, mais uma vez, foram semelhantes. Ambos entenderam que os resultados podem melhorar, desde que haja recursos tecnológicos e avanços no referencial teórico. 
0 objetivo da quinta pergunta era encaminhar uma atividade de preparação para a introdução de princípios da mentalidade enxuta nas práticas das empresas. 0 grupo 1 informou que teria problemas com tal atividade, podendo participar apenas em parte. Alegam que a cultura interna talvez bloqueie uma atividade formalizada, mas toleraria se a mesma fosse conduzida informalmente. Os demais grupos adeririam, sem restrições. Após a leitura, a resposta do grupo 1 variou, aceitando participar de uma atividade de benchmarking estruturado, aprendendo de modo indutivo. Os demais grupos também preferiram um modo indutivo de aprendizagem, principalmente apoiado em processo de benchmarking com operações de fabricação. Apenas o grupo 2 não descartou atividades universitárias.

\subsection{Discussão da segunda parte}

0 método de pesquisa pareceu ter motivado os integrantes dos grupos, pois, mesmo com as reuniões tendo ultrapassado o tempo combinado, não houve reação negativa. Ao final, as conclusões pareceram refletir o teor das discussões. Resta em aberto se a precisão dos dados e conclusões seriam superiores caso as reuniões tivessem sido filmadas.

0 resultado da pesquisa confirmou a primeira parte, que apontou diferenças gerenciais entre operadoras. Uma conclusão contributiva é quanto à preferência da indústria por abordagens indutivas e pela técnica do benchmarking. A indústria parece preparada para modificar práticas de gestão, porém enfrenta problemas com formatos explícitos de conhecimento, e, por decorrência, com abordagens

Quadro 1. Informações sinóticas.

\begin{tabular}{|c|c|c|c|c|c|}
\hline & Pergunta 1 & Pergunta 2 & Pergunta 3 & Pergunta 4 & Pergunta 5 \\
\hline $\begin{array}{l}\text { Construtos } \\
\text { investigados }\end{array}$ & $\begin{array}{l}\text { perdas } \\
\text { empresariais }\end{array}$ & $\begin{array}{l}\text { especificação de } \\
\text { valor }\end{array}$ & $\begin{array}{l}\text { fluxo contínuo e } \\
\text { balanceado, melhoria } \\
\text { contínua }\end{array}$ & $\begin{array}{l}\text { melhoria } \\
\text { contínua }\end{array}$ & $\begin{array}{l}\text { metodologia de } \\
\text { construção do } \\
\text { conhecimento } \\
\text { e aprendizado } \\
\text { organizacional }\end{array}$ \\
\hline $\begin{array}{l}\text { Construtos } \\
\text { encontrados }\end{array}$ & - & $\begin{array}{l}\text { especificação do } \\
\text { valor }\end{array}$ & $\begin{array}{l}\text { especificação do valor, } \\
\text { fluxo contínuo e } \\
\text { balanceado, melhoria } \\
\text { contínua }\end{array}$ & - & $\begin{array}{l}\text { método } \\
\text { indutivo, } \\
\text { benchmarking }\end{array}$ \\
\hline $\begin{array}{l}\text { Resumo das } \\
\text { respostas do } \\
\text { grupo } 1 \text { após } \\
\text { a leitura }\end{array}$ & $\begin{array}{l}\text { ousadia, } \\
\text { determinação, } \\
\text { métodos de } \\
\text { gestão }\end{array}$ & $\begin{array}{l}\text { esforços fora } \\
\text { de foco e } \\
\text { investimentos } \\
\text { onde o cliente } \\
\text { não vê }\end{array}$ & $\begin{array}{l}\text { medição do resultado } \\
\text { ruim, divergências } \\
\text { nos focos de trabalho, } \\
\text { visões exclusivas, sem } \\
\text { abordagem estruturada, } \\
\text { só apaga incêndios, } \\
\text { descrença }\end{array}$ & $\begin{array}{l}\text { desenvolvimento } \\
\text { insuficiente } \\
\text { de recursos } \\
\text { humanos }\end{array}$ & - \\
\hline $\begin{array}{l}\text { Resumo das } \\
\text { respostas do } \\
\text { grupo } 2 \text { após } \\
\text { a da leitura }\end{array}$ & $\begin{array}{l}\text { gerenciamento } \\
\text { eficaz, } \\
\text { capacidade de } \\
\text { aprender com } \\
\text { os erros }\end{array}$ & $\begin{array}{l}\text { globalização, } \\
\text { transformações } \\
\text { políticas, abertura } \\
\text { de mercados, } \\
\text { esforços fora de } \\
\text { foco }\end{array}$ & $\begin{array}{l}\text { resultado pode ser } \\
\text { melhor, medição do } \\
\text { resultado OK, sabe focar } \\
\text { esforços, abordagens } \\
\text { permanentes, com } \\
\text { resultados continuados }\end{array}$ & $\begin{array}{l}\text { análise de } \\
\text { processo e } \\
\text { modificações } \\
\text { baseasas na } \\
\text { busca de não- } \\
\text { conformidades }\end{array}$ & - \\
\hline $\begin{array}{l}\text { Resumo das } \\
\text { respostas do } \\
\text { grupo } 3\end{array}$ & $\begin{array}{l}\text { foco no } \\
\text { negócio, } \\
\text { determinação }\end{array}$ & $\begin{array}{l}\text { ineficiência de } \\
\text { processos }\end{array}$ & $\begin{array}{l}\text { resultado pode ser } \\
\text { melhor, medição do } \\
\text { resultado Ok, foco } \\
\text { insuficiente, abordagens } \\
\text { permanentes, com } \\
\text { resultados continuados }\end{array}$ & $\begin{array}{l}\text { recursos } \\
\text { tecnológicos } \\
\text { e avanço no } \\
\text { referencial } \\
\text { teórico }\end{array}$ & - \\
\hline $\begin{array}{l}\text { Resumo das } \\
\text { respostas do } \\
\text { grupo } 4\end{array}$ & $\begin{array}{l}\text { gerenciamento } \\
\text { eficaz, análise } \\
\text { de processo }\end{array}$ & novas tecnologias & $\begin{array}{l}\text { resultado pode ser } \\
\text { melhor, medição do } \\
\text { resultado OK, foco } \\
\text { insuficientes, abordagens } \\
\text { permanentes, com } \\
\text { resultados continuados }\end{array}$ & $\begin{array}{l}\text { recursos } \\
\text { tecnológicos } \\
\text { e avanço no } \\
\text { referencial } \\
\text { teórico }\end{array}$ & - \\
\hline
\end{tabular}


Quadro 2. Efeitos de transição da leitura.

\begin{tabular}{|c|c|c|c|c|c|}
\hline Palavras-chave & Pergunta 1 & Pergunta 2 & Pergunta 3 & Pergunta 4 & $\begin{array}{l}\text { Tipologia de } \\
\text { conhecimento e } \\
\text { representação }\end{array}$ \\
\hline $\begin{array}{l}\text { Grupo } 1 \text { antes da } \\
\text { leitura }\end{array}$ & $\begin{array}{l}\text { Cultura; disciplina; } \\
\text { hierarquia; }\end{array}$ & $\begin{array}{l}\text { empobrecimento; } \\
\text { competição; } \\
\text { individualismo; }\end{array}$ & $\begin{array}{l}\text { concorrência } \\
\text { predatoria; } \\
\text { desunião; } \\
\text { mercado cadente; }\end{array}$ & \multirow{2}{*}{$\begin{array}{l}\text { gestão de } \\
\text { recursos humanos } \\
\text { insuficiente; }\end{array}$} & $\begin{array}{l}\text { de mítico para } \\
\text { empírico, tácito }\end{array}$ \\
\hline $\begin{array}{l}\text { Grupo } 1 \text { após a } \\
\text { leitura }\end{array}$ & $\begin{array}{l}\text { ousadia; } \\
\text { determinação; } \\
\text { gestão; }\end{array}$ & $\begin{array}{l}\text { falta de foco; } \\
\text { análise de valor; }\end{array}$ & $\begin{array}{l}\text { má medição; visão } \\
\text { exclusica; falta de } \\
\text { foco; descrença }\end{array}$ & & $\begin{array}{l}\text { de empírico para } \\
\text { científico, tácito }\end{array}$ \\
\hline $\begin{array}{l}\text { Grupo } 2 \text { antes da } \\
\text { leitura }\end{array}$ & $\begin{array}{l}\text { estratégia; } \\
\text { planejamento } \\
\text { estratégico; }\end{array}$ & $\begin{array}{l}\text { globalização; } \\
\text { abertura de } \\
\text { mercados; }\end{array}$ & $\begin{array}{l}\text { especificação de } \\
\text { valor; abordagens; }\end{array}$ & \multirow{2}{*}{$\begin{array}{l}\text { análise de } \\
\text { processo; } \\
\text { busca de não- } \\
\text { conformidades. }\end{array}$} & $\begin{array}{l}\text { de empírico para } \\
\text { científico, explícito }\end{array}$ \\
\hline $\begin{array}{l}\text { Grupo } 2 \text { após a } \\
\text { leitura }\end{array}$ & $\begin{array}{l}\text { gerenciamento; } \\
\text { aprendizagem. }\end{array}$ & $\begin{array}{l}\text { globalização; falta } \\
\text { de foco. }\end{array}$ & $\begin{array}{l}\text { especifícação de } \\
\text { valor; abordagens } \\
\text { estruturadas }\end{array}$ & & científico, explícito \\
\hline
\end{tabular}

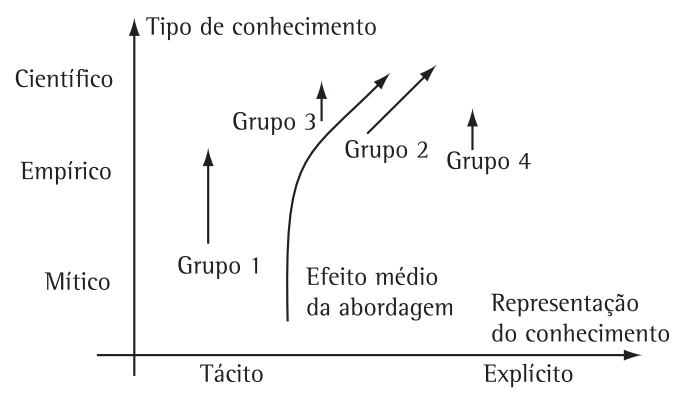

Figura 4. Efeito de transição.

dedutivas. Desse modo, a abordagem indutiva, com estudos de casos de sucesso em outras indústrias, pode ser viável para um programa que anteceda modificações nas práticas atuais. 0 método de aprendizagem que seria mais bem aceito é o método indutivo, apoiado em programa de benchmarking estruturado.

No Quadro 1, foram sintetizadas as principais informações obtidas, palavras-chaves para as respostas dos grupos, os objetivos visados pelos pesquisadores e os alcançados. A análise sinótica dos efeitos da leitura do texto nos grupos 1 e 2 surge no Quadro 2.

Nos grupos 1 e 2, a transição foi forçada e localizável, pela leitura de texto. Nos grupos 3 e 4, ao fim de cada pergunta, o conceito subjacente era introduzido e uma discussão se iniciava. As transições são mais fortes nos grupos 1 e 2 , mas não são desprezíveis em 3 e 4.

Seguem considerações necessárias para a análise.

- 0 conhecimento pode ser mítico, empírico ou científico. 0 conhecimento mítico nasce de verdades definitivas, que não admitem revisões por reflexão ou experimentos. 0 conhecimento empírico nasce da realidade, inclui crenças e opiniões, atende objetivos práticos, é construído sensorialmente e revisado por experimentos. 0 conhecimento científico é sistemático e organizado, avança quando sua inexatidão é demonstrada por experimentos, parte da observação da realidade para a abstração modeladora e volta para a observação para teste do modelo, em ciclo evolutivo (MÁTTAR NET0, 2002). 0 conhecimento organizacional é uma crença justificada vigente no ambiente organizacional que fundamenta mudanças. Ele é criado pelos indivíduos, mas é a organização que propicia o contexto criativo, por processos de ampliação do conhecimento individual, cristalizando-o como acervo organizacional. Esse processo pode ser tácito, integrado aos indivíduos, ao contexto e à cultura, ou explícito, ao assumir uma codificação transportável e replicável (NONAKA; TAKEUCHI, 2000).

- Os efeitos da transição são apresentados na Figura 4. 0 eixo vertical parte do conhecimento mítico, passa pelo empírico e chega ao científico. 0 eixo horizontal sai do conhecimento tácito e chega ao explícito. As transições observadas são representadas pelos caminhos no plano. Concluiu-se que o efeito da leitura foi aumentar o conhecimento científico em todos os casos e aumentar a representação explícita no grupo 2 .

\section{Considerações finais}

0 objetivo da pesquisa foi identificar como abordar a indústria do transporte coletivo ao introduzir princípios da mentalidade enxuta nas práticas de gestão das empresas. Para o estudo, foi escolhida a indústria do transporte coletivo de Porto Alegre, composta por 15 empresas.

$\mathrm{Na}$ primeira parte, mensurou-se, por survey, quanto dos princípios já estavam presentes nas 
empresas. As respostas serviram para separá-las em três aglomerados, segundo a presença dos princípios: forte, média, fraca. A confiabilidade das respostas, a aglomeração dos respondentes e a distribuição da presença dos princípios foram satisfatórias. Não foi possível descartar uma distribuição normal para a presença da mentalidade enxuta nas empresas e chegou-se a um intervalo de confiança para a grandeza mensurada. A mensuração ofereceu um panorama sobre a presença da mentalidade enxuta nas empresas individuais, e na indústria como um todo.

$\mathrm{Na}$ segunda parte, foram conduzidos estudos de caso em uma empresa do aglomerado fraco, uma do forte, na associação de classe e na operadora pública. A técnica foi o grupo focado. Dessa parte, emergiu a principal conclusão objetivada pela pesquisa. Se estimulada, a indústria apresenta boa capacidade de aprendizado. É provável que rejeite uma abordagem dedutiva, do tipo que contenha atividades universitárias ou de educação formal. No entanto, é provável que aceite uma abordagem prática, indutiva, do tipo hands-on, principalmente se for baseada em um programa de benchmarking estruturado que inclua operações de fabricação de classe mundial.

Como continuidade, pode-se formalizar 0 programa de preparação e as alternativas de gestão para a indústria, incluindo os princípios da mentalidade enxuta aplicados ao transporte coletivo. Também, pode-se considerar a complexidade da situação estudada e introduzir não linearidades, realimentações e correlações no modelo, chegando a uma representação mais completa da presença da mentalidade enxuta em empresas de transporte coletivo. Os resultados podem ser transferidos para outras atividades. 0 questionário, com algumas modificações, já foi aplicado e ofereceu alternativas de ação, em produção de móveis sob medida e armazenamento de petroquímicos.

\section{Referências}

ARNHEITER, E.; MALEYEFF, J. The integration of lean management and Six Sigma. The TQM Magazine, v. 17, n. 1, p. 5-18, 2005.

Associação Nacional das Empresas de Transportes Urbanos NTU. Anuário 2007/2008. Disponível em: <http://www. ntu.org.br>. Acesso em: Abril 2009.

Associação Nacional de Transportes Públicos - ANTP. Transporte humano: cidades com qualidade de vida. São Paulo: ANTP, 1999.

Associação Nacional de Transportes Públicos - ANTP. $O$ transporte na cidade do século 21. São Paulo: ANTP, 2001. Disponível em: <http://www.antp.org.br/TELAS/ transporte/transporte.htm>. Acesso: Agosto 2004.
AZAMBUJA, A. Análise de eficiência na gestão do transporte urbano por ônibus em municipios brasileiros. Florianópolis, 2002. Tese (Doutorado em Engenharia de Produção) - Universidade Federal de Santa Catarina UFSC.

BHASIN, S.; BURCHER, P. Lean viewed as a philosophy. Journal of Manufacturing Technology Management, v. 17, n. 1, p. 56-72, 2006.

BORCHARDT, M.; SELLITTO, M.; PEREIRA, G. Instrumento de avaliação para melhorias em processos organizacionais: caso do transporte coletivo rodoviário urbano de Porto Alegre. Produção, v. 17, n. 2, p. 302-316, 2007.

BOWEN, D.; YOUNGDAHL, W. Lean service: in defense of a production-line approach. International Journal of Service Industry Management, v. 9, n. 3, p. 207-225, 1998.

COMM, C.; MATHAISEL, D. A case study in applying lean sustainability concepts to universities. International Journal of Sustainability in Higher Education, v. 6, n. 2, p. 134-144, 2005.

COSTA, M. et al. Estudo comparativo entre empresas de ônibus utilizando AHP: o caso das empresas consorciadas de Porto Alegre. In: NASSI, C. et al. (Org.). Transportes. experiências em rede. Rio de Janeiro: FINEP, 2001.

DAVIS, M.; AQUILANO, N.; CHASE, R. Fundamentos da administração da produção. Porto Alegre: Bookman, 2001.

EMILIANI, M. L. Origins of lean management in America: the role of Connecticut businesses. Journal of Management History, v. 12, n. 2, p. 167-184, 2006.

Empresa Pública de Transporte e Circulação de Porto Alegre EPTC. Disponível em: <http://www.eptc.com.br>. Acesso em: Junho 2007.

ENSSLIN, L.; MONTIBELLER, G.; NORONHA, S. Apoio à decisão. Florianópolis: Insular, 2001.

FRENCH, S. Decision theory: an introduction to the mathematics of rationality. West Sussex: Ellis Horwood, 1986.

FULLERTON, R.; McWATTERS, C.; FAWSON, C. An examination of the relationship between JIT and financial performance. Journal of Operations Management, v. 21, n. 4, p. 383-404, 2003.

GOMES, L.; ARAYA, M.; CARIGNANO, C. Tomada de decisão em cenários complexos. São Paulo: Thomson, 2004.

HAIR, J. et al. Multivariate data analysis. New Jersey: Prentice Hall, 1998.

HENDERSON, B.; LARCO, J. Lean transformation: how to change your business into a lean enterprise. Richmond: The Oaklea Press, 2002.

HINES, P.; HOLWEG, M.; RICH, N. A review of contemporary lean thinking. International Journal of Operations and Production Management, v. 24, n. 10, p. 994-1011, 2004.

HINES, P.; TAYLOR, D. Enxugando a empresa: um guia para implementação. São Paulo: IMAM, 2000.

HOGART, R. Judgement and choice. Essex: John Wiley and Sons, 1988.

JACKSON, T.; JONES, K. Implementing a lean management system. Portland: Productivity Press, 1996.

JAMES-MOORE, S. M.; GIBBONS, A. Is lean manufacture universally relevant? An investigative methodology. 
International Journal of Operations and Production Management, v. 17, n. 9, p. 899-911, 1997.

KAYNAK, $H$. The relationship between total quality management practices and their effects on firm performance. Journal of Operations Management, v. 21, n. 4, p. 405-435, 2003.

KHISTY, C.; ARSLAN, T. Possibilities of steering the transportation planning process inthe face of bounded rationality and unbounded uncertainty. Transportation Research Part C: Emerging Technologies, v. 13, n. 2, p. 77-92, 2005.

LEWIS, M. Lean production and sustainable competitive advantage. International Journal of Operations and Production Management, v. 20, n. 8, p. 959-978, 2000.

MALEYEFF, J. Exploration of internal service systems using lean principles. Management Decision, v. 44, n. 5, p. 674-689, 2006.

MALHOTRA, N. Pesquisa de marketing: uma orientação aplicada. Porto Alegre: Bookman, 2001.

MÁTTAR NETO, J. Metodologia científica na era da informática. São Paulo: Saraiva, 2002.

NONAKA, I.; TAKEUCHI, H. Criação de conhecimento na empresa. Rio de Janeiro: Campus, 2000.

PARASURAMAN, A. Service quality and productivity: a synergistic perspective. Managing Service Quality, v. 12, n. 1, p. 6-9, 2002.

PRAJOGO, D.; McDERMOTT, C. The relationship between total quality management practices and organizational culture. International Journal of Operations and Production Management, v. 25, n. 11, p. 1101-1122, 2005.

PEREIRA, J. Análise de dados qualitativos. São Paulo: Edusp, 1999.

PORTER, M. Vantagem competitiva: criando e sustentando um desempenho superior. Rio de Janeiro: Campus, 1999.

REA, L.; PARKER, R. Metodologia de pesquisa. São Paulo: Pioneira, 2002.
RIBEIRO, J.; NEWMANN, C. Planejamento e condução de grupos focados. In: RIBEIRO, J. (Org.). Grupos focados: teoria e aplicações. Porto Alegre: FEENG/UFRGS/PPGEP, 2003.

ROTHER, M.; SHOOK, J. Aprendendo a enxergar. mapeando o fluxo de valor para agregar valor e eliminar o desperdício. São Paulo: Lean Institute Brasil, 1999.

SÁNCHEZ, A.; PÉREZ, M. Lean indicators and manufacturing strategies. International Journal of Operations and Production Management, v. 21, n. 11, p. 1433-1451, 2001.

SCHONBERGER, R. Building a chain of customer. New York: The Free Press, 1990.

SELLITTO, M.; BORCHARDT, M. Medição e controle do relacionamento de usuários com o objeto de serviço na indústria de transporte coletivo de passageiros. In: ENCONTRO NACIONAL DE ENGENHARIA DE PRODUÇÃO - ENEGEP, 24, 2004. Anais...

SELLITTO, M.; RIBEIRO, J. Construção de indicadores para avaliação de conceitos intangíveis em sistemas produtivos. Gestão e Produção, v. 11, n. 1, p. 75-90, 2004.

Sistema Transportador Sul - STS. Disponível em: <http:// www.sts.com.br>. Acesso em: Junho 2007.

SURESHCHANDAR, G.; CHANDRASEKHARAN, R.; ANANTHARAMAN, R. A holistic model for total quality service. International Journal of Service Industry Management, v. 12, n. 3, p. 378, 2001.

TREVILLE, S.; ANTONAKIS, J. Could lean production job design be intrinsically motivating? Contextual, configurational, and levels-f-analysis issues. Journal of Operations Management, v. 24, n. 2, p. 99-123, 2006.

WOMACK, J.; JONES, D. A mentalidade enxuta nas empresas. Rio de Janeiro: Campus, 1998.

YIN, R. Estudo de caso: planejamento e método. Porto Alegre: Bookman, 2001.

\title{
Presence of Lean Thinking principles and how to introduce them in the management of urban transport firms in Porto Alegre
}

\begin{abstract}
This paper presents a research into the presence of Lean Thinking principles in the management of urban transport firms in Porto Alegre. The procedures were: measurement of presence of Lean Thinking principles in management of urban transportation firms in Porto Alegre; reliability checks and clustering of firms according to the degree of presence; and case studies with clusters, class association and a public operator who influences the industry. The research discovered that the industry has learning capacity and would welcome an inductive approach based on benchmarking with world-class manufacturing operations, in order to enhance management. Also, the industry was less inclined to accept deductive approaches and academic activities in such a program.
\end{abstract}

Keywords

Lean Thinking in transportation. Benchmarking in transportation. Learning in transportation. 


\section{Apêndice 1: Questionário}

\section{Especificação de valor}

1. A empresa sabe que características têm seus clientes?

( ) Desconhece totalmente () Desconhece muito ( ) Conhece medianamente

() Conhece muito ( ) Conhece totalmente

2. A empresa sabe com que finalidade os clientes usam seus serviços?

( ) Desconhece totalmente ( ) Desconhece muito ( ) Conhece medianamente

( ) Conhece muito ( ) Conhece totalmente

3. A empresa sabe que fatores fazem os clientes decidir pelo uso de seus serviços?

() Desconhece totalmente ( ) Desconhece muito ( ) Conhece medianamente

() Conhece muito ( ) Conhece totalmente

4. A empresa sabe em que momento (horários, dias da semana ou do mês) os clientes usam mais ou menos os serviços?

() Desconhece totalmente () Desconhece muito () Conhece medianamente

( ) Conhece muito ( ) Conhece totalmente

5. A empresa sabe quanto, em que ritmo (viagens/hora, viagens/dia), os clientes usam seus serviços?

() Desconhece totalmente () Desconhece muito ( ) Conhece medianamente

( ) Conhece muito ( ) Conhece totalmente

6. A empresa sabe onde, em que locais, os clientes usam seus serviços?

() Desconhece totalmente () Desconhece muito ( ) Conhece medianamente

() Conhece muito ( ) Conhece totalmente

\section{Aceleração da cadeia de valor}

7. A empresa conhece o conceito de perdas empresariais?

( ) Desconhece totalmente () Desconhece muito ( ) Conhece medianamente

() Conhece muito () Conhece totalmente

8. A empresa conhece suas perdas empresariais?

() Desconhece totalmente () Desconhece muito ( ) Conhece medianamente

( ) Conhece muito ( ) Conhece totalmente

9. A empresa tipifica (classifica) suas perdas empresariais?

( ) Todas ( ) Muitas ( ) Algumas ( ) Poucas ( ) Não faz

10. A empresa mede e conhece o valor de suas perdas empresariais?

() Desconhece totalmente () Desconhece muito ( ) Conhece medianamente

() Conhece muito ( ) Conhece totalmente

11. A empresa tem e aplica um mecanismo formal para eliminar suas perdas empresariais?

( ) Nunca () Poucas vezes ( ) Algumas vezes ( ) Muitas vezes ( ) Sempre

12. Para a empresa é melhor um processo ser:

( ) Correto ( ) Mais correto que veloz ( ) Equilibrado ( ) Mais veloz que correto ( ) Veloz

\section{Tornar o fluxo contínuo e consistente}

13. A empresa conhece todos os seus processos internos?

() Desconhece totalmente () Desconhece muito () Conhece medianamente

() Conhece muito () Conhece totalmente 
14. A empresa tem mapas de seus processos internos?

( ) Nunca ( ) Poucas vezes ( ) Algumas vezes ( ) Muitas vezes ( ) Sempre

15. A empresa mede o resultado de seus processos internos?

( ) Nunca ( ) Poucas vezes ( ) Algumas vezes ( ) Muitas vezes ( ) Sempre

16. A empresa mede o resultado dos processos de empresas parceiras?

( ) Nunca ( ) Poucas vezes ( ) Algumas vezes ( ) Muitas vezes ( ) Sempre

17. A empresa modifica os recursos produtivos (mão de obra, equipamentos, materiais, empresas parceiras) de acordo com o resultado de seus processos internos?

( ) Nunca ( ) Poucas vezes ( ) Algumas vezes ( ) Muitas vezes ( ) Sempre

18. A empresa prefere recursos produtivos (mão de obra, equipamentos, materiais):

( ) Altamente especializados ( ) Mais especializados que generalistas ( ) Equilibrado

() Mais generalistas que especializados ( ) Altamente generalistas

\section{Produção puxada}

19. A empresa possui e aplica um mecanismo para coletar a opinião do cliente?

( ) Nunca ( ) Poucas vezes ( ) Algumas vezes ( ) Muitas vezes ( ) Sempre

20. A empresa analisa a opinião e os pedidos dos clientes?

( ) Nunca ( ) Poucas vezes ( ) Algumas vezes ( ) Muitas vezes ( ) Sempre

21. A empresa atende os pedidos pertinentes dos clientes?

( ) Nunca ( ) Poucas vezes ( ) Algumas vezes ( ) Muitas vezes ( ) Sempre

22. A empresa modifica seus processos internos para atender pedidos de clientes?

( ) Nunca () Poucas vezes ( ) Algumas vezes ( ) Muitas vezes ( ) Sempre

23. A empresa informa o cliente quando atende um pedido seu?

() Nunca ( ) Poucas vezes ( ) Algumas vezes ( ) Muitas vezes ( ) Sempre

24. Nos últimos 24 meses, quantas modificações foram feitas atendendo pedidos de clientes?

( ) Nenhuma ( ) Poucas ( ) Algumas ( ) Muitas ( ) Todas

\section{Rumo à perfeição}

25. A empresa conhece o conceito de melhoria contínua?

() Desconhece totalmente () Desconhece muito ( ) Conhece medianamente

() Conhece muito ( ) Conhece totalmente

26. A empresa tem e aplica um mecanismo formal para promover a melhoria contínua?

() Nunca () Poucas vezes ( ) Algumas vezes ( ) Muitas vezes ( ) Sempre

27. A empresa tem e aplica um mecanismo formal focalizador de melhoria contínua?

() Nunca () Poucas vezes ( ) Algumas vezes ( ) Muitas vezes ( ) Sempre

28. A empresa tem e persegue metas de melhoria contínua?

( ) Nunca ( ) Poucas vezes ( ) Algumas vezes ( ) Muitas vezes ( ) Sempre

29. A empresa tem e aplica um mecanismo formal para recompensar a melhoria contínua?

( ) Nunca ( ) Poucas vezes ( ) Algumas vezes ( ) Muitas vezes ( ) Sempre

30. Nos últimos 24 meses quantos indicadores apresentaram melhoria contínua?

( ) Nenhum ou não possui indicadores ( ) Poucos ( ) Alguns ( ) Muitos ( ) Todos 